\title{
A Nonlinear Model to Study Selectively Deformable Wing of an Aircraft
}

\author{
Deiva Ganesh A \\ Department of Mechanical Engineering, RMK College of Engineering and Technology \\ Chennai, Tamil Nadu, India
}

\begin{tabular}{l} 
Article Info \\
Article history: \\
Received Jul 23, 2015 \\
Revised Oct 28, 2015 \\
Accepted Nov 19, 2015 \\
\hline Keyword: \\
Aircraft \\
Degree Of Freedom (DOF) \\
Nonlinear Model \\
Selectively Deformable \\
Structure (SDS) \\
Study Selectively
\end{tabular}

Corresponding Author:

Deiva Ganesh A,

Department of Mechanical Engineering,

RMK College of Engineering and Technology,

Chennai, Tamil Nadu, India.

Email: amdganesh@yahoo.co.in

\begin{abstract}
Aeroelasticity of an aircraft includes the study of dynamics of prime movers, structural dynamics, and aerodynamics. Research efforts are on in every area to improve the overall performance of an aircraft. In this paper preliminary studies conducted on the dynamics of selectively deformable wing using an under actuated nonlinear model is reported. First, the literature related to the design and analysis of selectively deformable structure (SDS) wing is reviewed. Second, a single degree of freedom (DOF) model to represent a fixed wing and a two DOF under-actuated model to represent SDS are discussed and their mathematical models are derived. Third, the effect of deformable wing portion on the wing dynamics is studied by varying the excitation frequency and stiffness of the model. Fourth, an experimental setup consisting of two rigid links connected by spring and subjected to sinusoidal displacement is investigated. Final section summarizes the research and provides directions for future work.
\end{abstract}

Copyright $(2015$ Institute of Advanced Engineering and Science. All rights reserved.

\section{INTRODUCTION}

In the last hundred years airplane technology has grown from strut and wire biplanes propeller driven to jet propelled airplane, Anderson [1]. With the intense study on aerodynamics, the advancement of composite materials, control, sensing, and communication technologies supersonic and hypersonic airplanes are realized. The availability of analysis tools like FEA and CFD has helped in carrying out structural, aeroelasticity analysis of aircraft structures resulting in improved lift/drag ratio, high aspect ratio wing design and light weight high-speed airplanes. Presently, research efforts are undergoing to realize the desired aeroelastic deformation through surface morphing, all movable control surfaces with variable stiffness effects and with selectively deformable structures. The following describes the literature related to aeroelasticity.

Amiryants et al. [2] investigates the morphing of airframe structures using selectively deformable structures (SDS). The main objective of SDS research is to develop a structure which has a minimal Poisson's effect: results in a deflection along the direction of the acting load. Simpson et al. [3] provide a review of research project on "active aeroelastic aircraft structures" (3AS). The aims of the project are as follows:

a. Aerodynamic drag reduction.

b. Structural weight reduction.

c. Advanced sizing design and exploitation.

d. Tool reduction.

e. Reduced maintenance.

f. High aeroelastic efficiency. 
g. Improved aeroelastic stability and dynamic loads suppression.

Braidruski et al. [4] experiments the usefulness of SMA actuators for morphing wing to reduce fuel consumption and to improve aerodynamic performance. They have used a morphed wing proto-type combined with three sub-systems namely flexible extrudes, rigid intrude and an actuator group control inside the wing box. Kuzmina et al. [5] presents an overview of the aeroelastic deformation using an adaptive stiffness attachements of all moveable aerodynamic surfaces. Amiryants et al.[6] presents the investigations on aerodynamic control using differential leading edge, forward aileron, special combination of spoiler and aileron Nagel et al.[7] presents the results of using active composites to enable shape control of the wing while retaining the stiffness and strength requirements. Amiryants [8] presents a comparison of control effectiveness of hinge-less connection of aileron using selectively deformable structure with traditional control devices. It is shown SDS is highly effective for wide range of mach numbers and dynamic pressure. Ahn et al. [9] presents the tilt-rotor technology developed for smart UAV. Their objective is to develop high speed VTOL aircraft and to tailor the technology for the domestic aerospace industry. Mauchar et al.[10] investigates use of active trailing edge of rotor blade control to minimize noise and vibration, also to reduce fuel consumption. Livne [11] presents an extensive review on aeroelasticity. He has discussed comprehensively the various issues and remedies, numerical simulation, modeling for capturing local and global behavior, order reduction of large FE and CFD models, sensitivity analysis of coupled structure, aerodynamic optimization with FE/CFD models, aeroservoelasticity and aeroservoelastic optimization, morphing, smart airplanes, accounting for uncertainty in aeroelastic analysis and design, multidisciplinary design optimization, aeroelasticity of selected non-conventional configurations, aeroelastic challenges associated with supersonic and hypersonic flight, flopping flight and UAVs.

From the literature it is clear that massive work have been done to improve aeroelasiticity. Recently, research efforts are on in the areas of surface morphing to improve aerodynamics, and minimization of control effort required to effect changes in the wing geometry using selectively deformable structure (SDS). Therefore, availability of an effective model to study SDS dynamics would greatly help in evolving better design for the SDS based wing. In this work a preliminary study has been conducted to understand the usefulness of duffing's equation to study SDS dynamics.

The organization of the paper is follows. In section one, literature related to aeroelasticity have been reviewed. Section two presents the dynamics of SDS using an under-actuated beam like model. Section three reports the simulation conducted on the fixed wing and SDS models. Section four presents the experimental results conducted on simple beam and selectively deformable beams. Final section summarizes the research work and outlines the plan for future work.

\section{THE MODEL}

A defense aircraft need to be accelerated and decelerated fast and at the same time wing geometry need to be modified to improve aerodynamic effectiveness. Compliance in the wing would help in reducing the control effort required to change the wing geometry. However, the effects of compliance on wing dynamics need to be understood, and for this purpose some simple models of wings are assumed and studies are carried out. Figure 1 and 2 shows the models of fixed wing and selectively deformable wing respectively. Fixed wing is represented by a simple cantilever beam and SDS wing is represented by a two DOF underactuate beam and both are subjected to excitation. The following describes the two models.

\subsection{Model-1}

Figure 1 shows the model representing the fixed wing. It consists of a single beam with one end fixed and a sinusoidal base excitation.

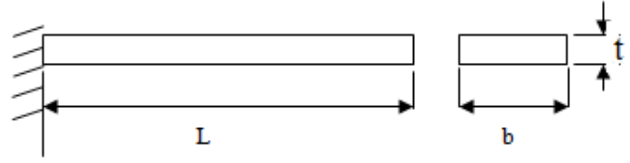

Figure 1. Cantilever beam model to represent fixed wing

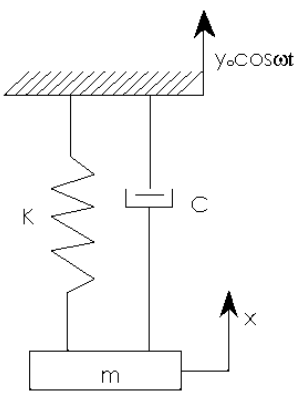

Figure 1a. Equivalent model to represent the fixed wing 
The equation of motion for the above model is given by,

$m \ddot{x}=-c(\dot{x}-\dot{y})-k(x-y)^{3}$

Now let $z=x-y$

Would results in

$$
\begin{aligned}
& m \ddot{z}+c \dot{z}+k z^{3}=-m \ddot{y} \\
& m \ddot{z}+c \dot{z}+k z^{3}=m \omega^{2} y_{0} \cos \omega t
\end{aligned}
$$

Where the parameters of the system are, m, c, k, E, l, I - mass, damping coefficient, equivalent stiffness, young's modulus, length, area moment of inertia of cross section of the beam respectively. [k $\left.=3 \mathrm{EI} / \mathrm{l}^{3}\right] \mathrm{x}, \mathrm{y}, \mathrm{z}-$ displacement at the tip, excitation amplitude, relative displacement between the mass and support respectively.

The above equation can be converted into two first order differential equations,

$$
\begin{aligned}
& \mathrm{z}_{1}=\dot{\mathrm{z}} \\
& \dot{z_{1}}=\frac{1}{m}\left[m \omega^{2} y_{0} \cos \omega t-c z_{1}-k z^{3}\right]
\end{aligned}
$$

\subsection{Model-2}

Figure 2 shows the under-actuated model representing the SDS wing. It consists of two beams connected by compliant arrangement and its fixed end actuated by a sinusoidal excitation.
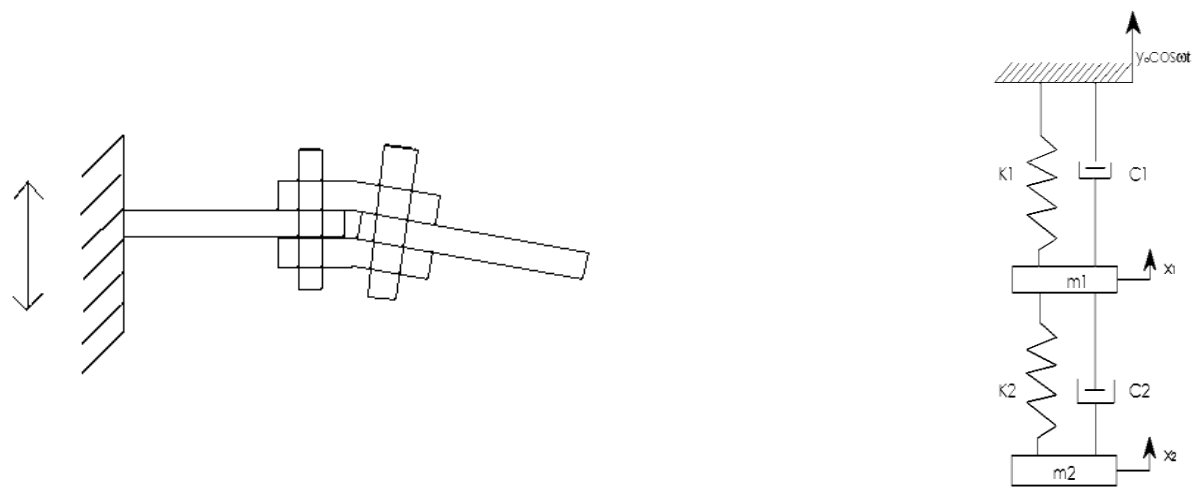

Figure 2. An under-actuated model to represent SDS wing
Figure 2a. The equivalent model for representing SDS wing

The equation of motion for the above model is given by,

$$
\begin{aligned}
& \mathrm{m}_{1} \ddot{\mathrm{x}_{1}}=-\mathrm{c}_{1}\left(\dot{\mathrm{x}_{1}}-\dot{\mathrm{y}}\right)-\mathrm{k}_{1}\left(\mathrm{x}_{1}-\mathrm{y}\right)^{3}-\mathrm{c}_{2}\left(\dot{\mathrm{x}_{1}}-\dot{\mathrm{x}_{2}}\right)-\mathrm{k}_{2}\left(\mathrm{x}_{1}-\mathrm{x}_{2}\right)^{3} \\
& \mathrm{~m}_{2} \ddot{\mathrm{x}_{2}}=-\mathrm{c}_{2}\left(\dot{\mathrm{x}_{2}}-\dot{\mathrm{x}_{1}}\right)-\mathrm{k}_{2}\left(\mathrm{x}_{2}-\mathrm{x}_{1}\right)^{3}
\end{aligned}
$$

Where,

$\mathrm{m}_{1}, \mathrm{~m}_{2}$ - mass of the beam 1 and 2

$\mathrm{k}_{1}, \mathrm{k}_{2}$ - stiffness of the beam1 and the compliant arrangement

$\mathrm{c}_{1}, \mathrm{c}_{2}$ - damping coefficient of beam1and the compliant arrangement

$\mathrm{y}_{0}$ - excitation amplitude

$\mathrm{x}_{1}, \mathrm{x}_{2}$ - displacement of $\mathrm{m} 1, \mathrm{~m} 2$

$\dot{\mathrm{x}}_{1}, \dot{\mathrm{x}}_{2}$ - velocity of $\mathrm{m} 1$ and $\mathrm{m} 2$

$\ddot{\mathrm{x}}_{1}, \ddot{\mathrm{x}}_{2}$ - acceleration of $\mathrm{m} 1$ and $\mathrm{m} 2$ 
Now letting,

$\mathrm{z}=\mathrm{x}_{1}-\mathrm{y}$

$\dot{z}=\dot{x_{1}}-\dot{y}$

$\mathrm{w}=\mathrm{x}_{1}-\mathrm{x}_{2}$

$\ddot{w}=\ddot{x_{1}}-\ddot{x_{2}}$

$\ddot{\mathrm{x}}_{2}=\ddot{\mathrm{x}}_{1}-\ddot{\mathrm{w}}$

Where,

$\mathrm{z}, \dot{\mathrm{z}}, \ddot{\mathrm{z}}$ - relative displacement, velocity and acceleration between the beam and the mass 1 and 2 $\mathrm{w}, \dot{\mathrm{W}}, \ddot{\mathrm{w}}$ - relative displacement, velocity and acceleration between the beam and the mass 1 and 2 Would result in the following two $2^{\text {nd }}$ order equations,

$m_{1} \ddot{z}+c_{1} \dot{z}+k_{1} z^{3}+k_{2} w^{3}+c_{2} \dot{w}=-m_{1} \ddot{y}$

$m_{2} \ddot{w}+c_{2} \dot{w}+k_{2} w^{3}=m_{2} \ddot{x}_{1}$

\begin{tabular}{lccc}
\hline $\begin{array}{l}\text { Sl. } \\
\text { no }\end{array}$ & $\begin{array}{c}\text { Excitation } \\
\text { frequency, } \\
\text { w rads/sec }\end{array}$ & $\begin{array}{c}\text { Tip } \\
\text { Displacement } \\
\text { Y }_{1} \text { in m }\end{array}$ & $\begin{array}{c}\text { Tip } \\
\text { Velocity } \\
\text { Y }_{2} \text { in m/sec }\end{array}$ \\
\hline 1 & 100 & 0.5841 & 20.0766 \\
2 & 200 & 0.5913 & 40.0519 \\
3 & 300 & 0.5957 & 60.0857 \\
4 & 400 & 0.5967 & 80.0862 \\
5 & 500 & 0.5951 & 100.0850 \\
6 & 600 & 0.5978 & 120.0827 \\
7 & 700 & 0.5972 & 140.1059 \\
8 & 800 & 0.5957 & 160.1250 \\
9 & 900 & 0.5954 & 180.1372 \\
10 & 1000 & 0.5965 & 200.1361 \\
\hline
\end{tabular}

Again letting,

$\dot{Z}=z_{1}$

$\dot{w}=w_{1}$

Will result in four first order equations,

$\dot{z}=z_{1}$

$\dot{z}_{1}=\frac{1}{m_{1}}\left[m_{1} \omega^{2} y_{0} \cos \omega t-c z_{1}-k z_{1}^{2}-c_{2} w_{1}-k_{2} w^{3}\right]$

$\dot{w}=w_{1}$

$\dot{w}_{1}=\frac{1}{m_{2}}\left[m_{2}\left\{\frac{1}{m_{1}}\left[m_{1} \omega^{2} y_{0} \cos \omega t-c_{1}-k z_{1}{ }^{2}-c_{2} w_{1}-k_{2} w^{3}\right]\right\}-m_{2} \omega^{2} y^{2} \cos \omega t-c_{2} w_{1}-k_{2} w^{3}\right]$

Extensive work has been on solving duffing's equation and its dynamics. Harmonic balance in conjunction with Melnikov method [12], nonlinear dampers for improving structural dynamics [13-15] and nonlinear control design for vibration reduction [16]. This work makes an attempt to assess the usefulness of duffing's equation to study the dynamics of SDS wing. 


\section{SIMULATION}

Table 1. Simulation results for fixed wing $\left(\mathrm{m}=5 \mathrm{~kg}, \mathrm{k}=200 \mathrm{~N} / \mathrm{m}, \mathrm{c}=10 \mathrm{~N} / \mathrm{m} / \mathrm{sec}\right.$, Initial conditions $\mathrm{x}_{\mathrm{o}}=0.2 \mathrm{~m}$, $\dot{x}=0$, Excitation amplitude, $\mathrm{y}_{\mathrm{o}}=0.2 \mathrm{~m}$, simulation duration $\left.=10 \mathrm{secs}\right)$

\begin{tabular}{ccccccc}
\hline $\begin{array}{c}\text { S1. } \\
\text { No }\end{array}$ & $\begin{array}{c}\text { Excitation } \\
\text { frequency, } \omega \\
\text { rads/sec }\end{array}$ & $\begin{array}{c}\text { Displacement } \\
\text { Y1 m }\end{array}$ & $\begin{array}{c}\text { Velocity } \\
\text { Y2 m/sec }\end{array}$ & $\begin{array}{c}\text { Displacement } \\
\text { Y3 m }\end{array}$ & $\begin{array}{c}\text { Tip } \\
\text { Velocity } \\
\text { Y4 m/sec }\end{array}$ & $\begin{array}{c}\text { Tip } \\
\text { Displacement } \\
\text { Y1+y3 m }\end{array}$ \\
\hline 1 & 100 & 0.5554 & 19.9586 & 0.4618 & 15.9518 & 1.0172 \\
2 & 200 & 0.5754 & 40.0015 & 0.4872 & 31.9969 & 1.0626 \\
3 & 300 & 0.5851 & 60.0187 & 0.4985 & 48.0129 & 1.0836 \\
4 & 400 & 0.5888 & 80.0271 & 0.5039 & 64.0207 & 1.0927 \\
5 & 500 & 0.5884 & 100.0347 & 0.5045 & 80.0271 & 1.0929 \\
6 & 600 & 0.5925 & 120.0407 & 0.5092 & 96.0317 & 1.1017 \\
7 & 700 & 0.5927 & 140.0456 & 0.5103 & 112.0356 & 1.1030 \\
8 & 800 & 0.5919 & 160.0464 & 0.5103 & 128.0329 & 1.1022 \\
9 & 900 & 0.5917 & 180.0604 & 0.5099 & 144.0437 & 1.1016 \\
10 & 1000 & 0.5932 & 200.0698 & 0.5114 & 160.0511 & 1.1046 \\
\hline
\end{tabular}

Simulations are conducted to understand the effect of compliance on wing dynamics. In order to make comparison between fixed wing and selectively deformable wing both the model lengths are kept equal. For fixed wing there will be single stiffness and for SDS there will be two stiffnesses namely the stiffness of the link 1 and stiffness of the compliant arrangement. In the SDS model, the link 2 is joined with link1 through a compliant arrangement and the link 2 is assumed to be rigid. The excitation amplitude for both the models are kept constant and frequency is varied and the maximum velocity and displacement for each frequency are observed and tabulated. The table 1 and 2 show the maximum tip displacement and velocity values for fixed wing and SDS wing for various frequencies.

Table 2. Simulation results for SDS wing $\left(\mathrm{m}_{1}=2.5 \mathrm{~kg}, \mathrm{~m}_{2}=2.5 \mathrm{Kg}, \mathrm{k}_{1}=250 \mathrm{~N} / \mathrm{m}, \mathrm{k}_{2}=150 \mathrm{~N} / \mathrm{m}, \mathrm{c}_{1}=10 \mathrm{~N} / \mathrm{m} / \mathrm{sec}\right.$, $\mathrm{c}_{2}=10 \mathrm{~N} / \mathrm{m} / \mathrm{sec}$ Initial conditions $\mathrm{x}_{10}=0.2 \mathrm{~m}, \quad \dot{x}_{10}=0, \mathrm{x}_{20}=0.2 \mathrm{~m}, \dot{x}_{20}=0$, excitation amplitude $\mathrm{y}_{0}=0.2 \mathrm{~m}$ simulation duration $=10 \mathrm{secs}$ )

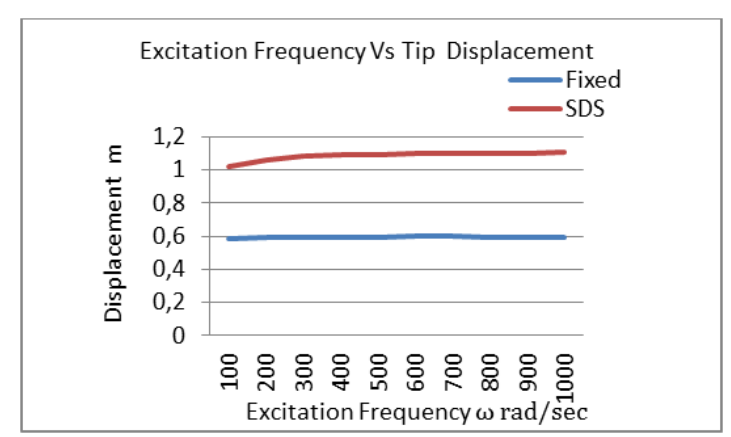

Figure 3. Excitation frequency Vs Displacement for fixed and SDS wings

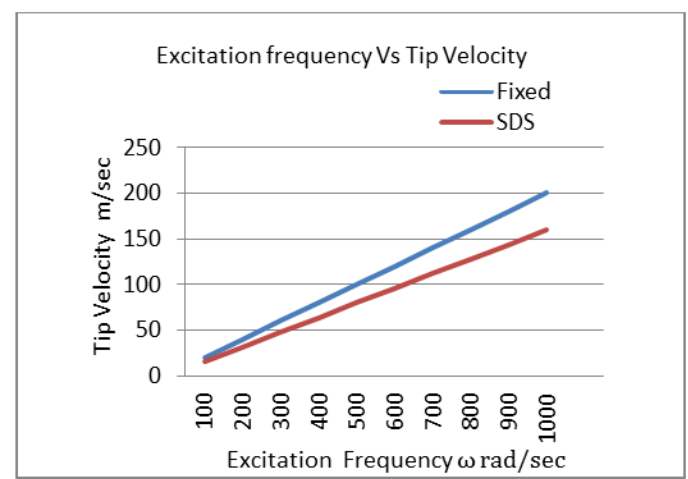

Figure 4. Excitation frequency Vs Tip Velocity for fixed and SDS wings 
Figure 3 and 4 show the graphs drawn between frequency Vs displacement and frequency Vs velocity for both type of wings. From the graph we can observe that,

a. Compliance in the link reduces the speeding capacity

b. For the particular frequency speeding capacity is better

c. Compliance in the wing increases displacement again it is more at certain frequency

Table 3. Displacement and Tip Velocity of SDS wing under stiffness variation while the excitation frequency is kept constant $\left(\mathrm{m}_{1}=2.5 \mathrm{~kg}, \mathrm{~m}_{2}=2.5 \mathrm{Kg}, \mathrm{k}_{1}=250 \mathrm{~N} / \mathrm{m}, \mathrm{k}_{2}=\right.$ variable, $\mathrm{c} 1=10 \mathrm{~N} / \mathrm{m} / \mathrm{sec}, \mathrm{c} 2=10 \mathrm{~N} / \mathrm{m} / \mathrm{sec}$ Initial conditions $\mathrm{x}_{1 \mathrm{o}}=0.2 \mathrm{~m}, \dot{x}_{1 \mathrm{o}}=0, \mathrm{x}_{2 \mathrm{o}}=0.2 \mathrm{~m}, \dot{x}_{2 \mathrm{o}}=0$, excitation amplitude $=0.2 \mathrm{~m}$ simulation duration $=10 \mathrm{secs}$ )

\begin{tabular}{cccccc}
\hline $\begin{array}{c}\text { Stiffness } \\
\text { K2 }\end{array}$ & $\begin{array}{c}\text { Displacement } \\
\text { Y1 m }\end{array}$ & $\begin{array}{c}\text { Velocity } \\
\text { Y2 } \\
\mathrm{m} / \mathrm{sec}\end{array}$ & $\begin{array}{c}\text { Displacement } \\
\text { Y3m }\end{array}$ & $\begin{array}{c}\text { Tip Velocity } \\
\text { Y4 m/sec }\end{array}$ & $\begin{array}{c}\text { Tip } \\
\text { Displacement } \\
\text { Y1+Y3 m }\end{array}$ \\
\hline 100 & 0.5556 & 19.9593 & 0.4622 & 15.9603 & 1.0178 \\
110 & 0.5556 & 19.9593 & 0.4621 & 15.9559 & 1.0177 \\
120 & 0.5555 & 19.9585 & 0.4620 & 15.9599 & 1.0175 \\
130 & 0.5555 & 19.9561 & 0.4620 & 15.9597 & 1.0175 \\
140 & 0.5554 & 19.9531 & 0.4619 & 15.9522 & 1.0173 \\
150 & 0.5554 & 19.9586 & 0.4618 & 15.9518 & 1.0172 \\
160 & 0.5553 & 19.9557 & 0.4617 & 15.9522 & 1.0170 \\
170 & 0.5553 & 19.9571 & 0.4617 & 15.9597 & 1.0170 \\
180 & 0.5553 & 19.9581 & 0.4616 & 15.9599 & 1.0169 \\
190 & 0.5552 & 19.9586 & 0.4615 & 15.9559 & 1.0167 \\
200 & 0.5552 & 19.9586 & 0.4614 & 15.9603 & 1.0166 \\
\hline
\end{tabular}

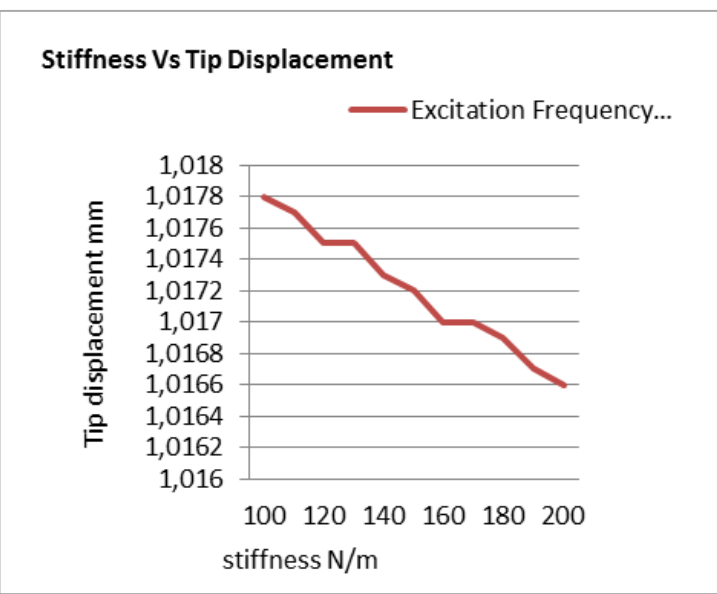

Figure 5. Stiffness Vs Tip Displacement for SDS wings

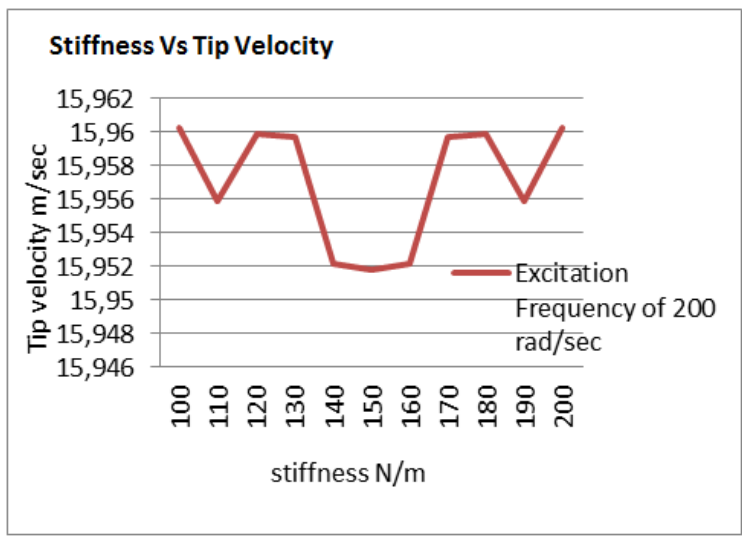

Figure 6. Stiffness Vs Tip Velocity for fixed and SDS wings 
From the Figure 5, it is clear that the increase in stiffness reduces deformation. Figure 6, shows that the tip velocity fluctuates with stiffness variation hinting at wing parameter tuning might improve aerodynamic performance.

\section{EXPERIMENTATION}

Here, the effects of compliance on the wing dynamics are studied experimentally. Figure 7 and 8 show the experimental setups for fixed and SDS wings respectively. It consists of a DC motor, variable speed controller, vertical stand with holder, an eccentric cam, fixed beam, selectively compliant beam, and the accelerometer with necessary instruments. Experiments are conducted on fixed wing and compliant wings. The motor speed is varied from $100 \mathrm{rpm}$ to $1000 \mathrm{rpm}$ and the displacement, velocity and acceleration values are noted and tabulated. Compliance in the beam is varied by varying the gap between two beams and the sensor position is also varied and the values are tabulated in tables 4,5 and 6 .

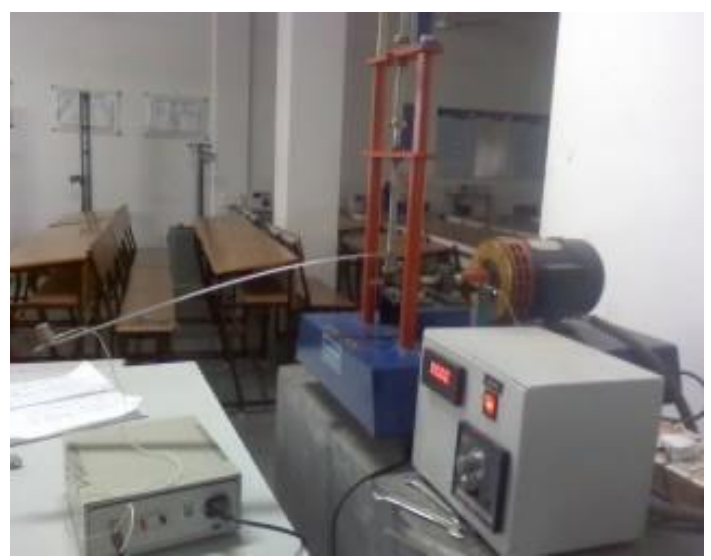

Figure 7. Experimental setup to study fixed wing dynamics

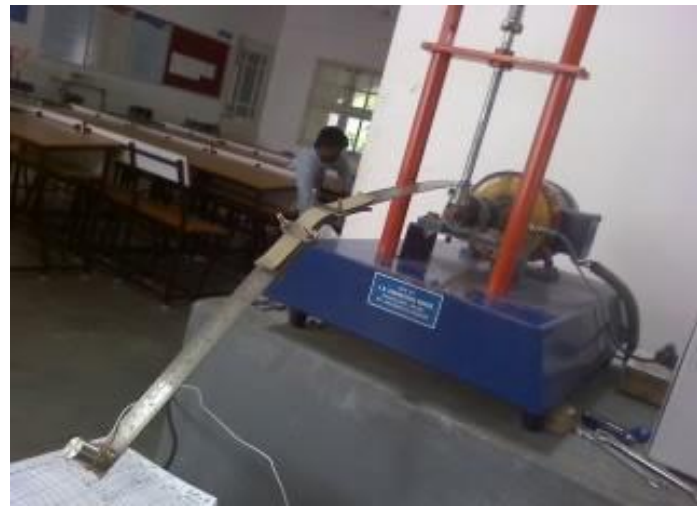

Figure 8. Experimental setup to study SDS wing

Table 4. Experimental results for fixed wing (60 cm standard steel rule is used as beam)

\begin{tabular}{cccccc}
\hline $\begin{array}{c}\text { Sl. } \\
\text { No }\end{array}$ & $\begin{array}{l}\text { Speed } \\
(\mathrm{rpm})\end{array}$ & $\begin{array}{l}\text { Acceleration } \\
\left(\mathrm{m} / \mathrm{s}^{2}\right)\end{array}$ & $\begin{array}{l}\text { Velocity } \\
(\mathrm{cm} / \mathrm{s})\end{array}$ & $\begin{array}{l}\text { Displaceme } \\
\mathrm{nt}(\mathrm{mm})\end{array}$ & $\begin{array}{l}\text { Frequency } \\
(\mathrm{hz})\end{array}$ \\
\hline 1 & 100 & 0.0 & 0.95 & 0.423 & 41 \\
2 & 200 & 1.2 & 0.64 & 0.430 & 41 \\
3 & 300 & 3.2 & 1.70 & 0.891 & 41 \\
4 & 400 & 5.9 & 2.07 & 1.000 & 41 \\
5 & 500 & 13.1 & 4.30 & 1.745 & 41 \\
6 & 600 & 38.7 & 7.89 & 2.295 & 41 \\
\hline
\end{tabular}


Table 5. Experimental results for SDS wing

$(30+1+30 \mathrm{~cm}$, standard $30 \mathrm{~cm}$ steels are connected by belt and used as SDS beam)

\begin{tabular}{cccccc}
\hline $\begin{array}{c}\text { Sl. } \\
\text { No. }\end{array}$ & $\begin{array}{l}\text { Speed } \\
(\mathrm{rpm})\end{array}$ & $\begin{array}{l}\text { Acceleration } \\
\left(\mathrm{m} / \mathrm{s}^{2}\right)\end{array}$ & $\begin{array}{l}\text { Velocity } \\
(\mathrm{cm} / \mathrm{s})\end{array}$ & $\begin{array}{l}\text { Displacement } \\
(\mathrm{mm})\end{array}$ & $\begin{array}{l}\text { Frequency } \\
(\mathrm{hz})\end{array}$ \\
\hline 1 & 100 & 0.2 & 0.12 & 0.136 & 41 \\
2 & 200 & 0.0 & 1.29 & 0.820 & 41 \\
3 & 300 & 6.0 & 14.40 & 6.747 & 41 \\
4 & 400 & 2.5 & 5.76 & 2.588 & 41 \\
5 & 500 & 3.2 & 4.53 & 1.879 & 41 \\
6 & 600 & 3.7 & 3.83 & 1.478 & 41 \\
7 & 700 & 4.8 & 3.47 & 1.230 & 41 \\
8 & 800 & 6.1 & 3.48 & 1.134 & 41 \\
9 & 900 & 9.3 & 3.75 & 1.077 & 41 \\
10 & 1000 & 9.2 & 4.07 & 1.139 & 41 \\
\hline
\end{tabular}

Table 6. Experimental results for SDS wing

$(30+2+30 \mathrm{~cm}$, standard $30 \mathrm{~cm}$ steels are connected by belt and used as SDS beam)

\begin{tabular}{cccccc}
\hline $\begin{array}{c}\text { S1. } \\
\text { No. }\end{array}$ & $\begin{array}{l}\text { Speed } \\
(\mathrm{rpm})\end{array}$ & $\begin{array}{l}\text { Acceleration } \\
\left(\mathrm{m} / \mathrm{s}^{2}\right)\end{array}$ & $\begin{array}{l}\text { Velocity } \\
(\mathrm{cm} / \mathrm{s})\end{array}$ & $\begin{array}{l}\text { Displacement } \\
(\mathrm{mm})\end{array}$ & $\begin{array}{l}\text { Frequency } \\
(\mathrm{hz})\end{array}$ \\
\hline 1 & 100 & 0.1 & 0.30 & 0.227 & 41 \\
2 & 200 & 0.1 & 0.81 & 0.502 & 41 \\
3 & 300 & 1.0 & 3.08 & 1.535 & 41 \\
4 & 400 & 7.8 & 12.36 & 5.269 & 41 \\
5 & 500 & 4.9 & 6.90 & 2.786 & 41 \\
6 & 600 & 4.8 & 5.10 & 1.947 & 41 \\
7 & 700 & 5.2 & 4.39 & 1.513 & 41 \\
8 & 800 & 6.6 & 3.90 & 1.236 & 41 \\
9 & 900 & 9.0 & 3.94 & 1.147 & 41 \\
10 & 1000 & 11.9 & 3.74 & 1.132 & 41 \\
\hline
\end{tabular}

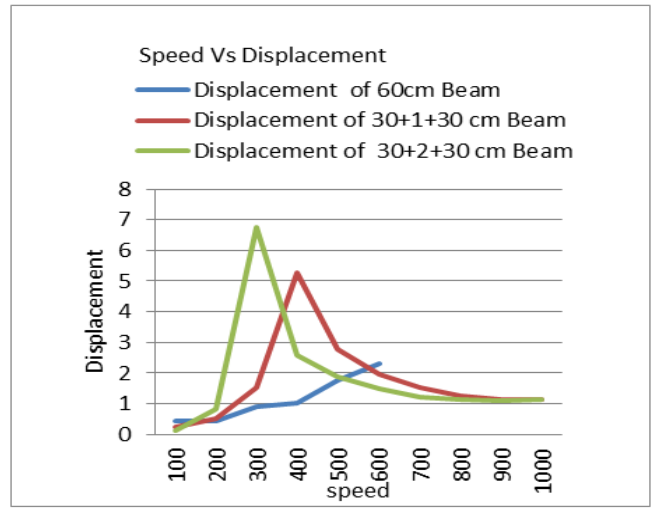

Figure 9. Comparison of Speed Vs Displacement

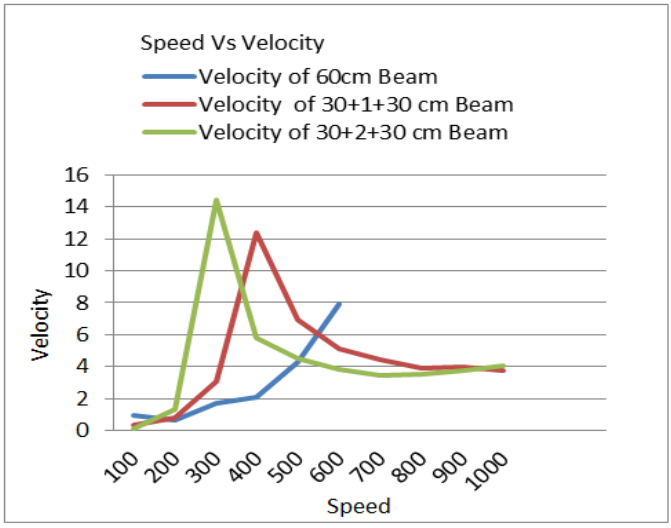

Figure 10. Comparison of Speed Vs Velocity 


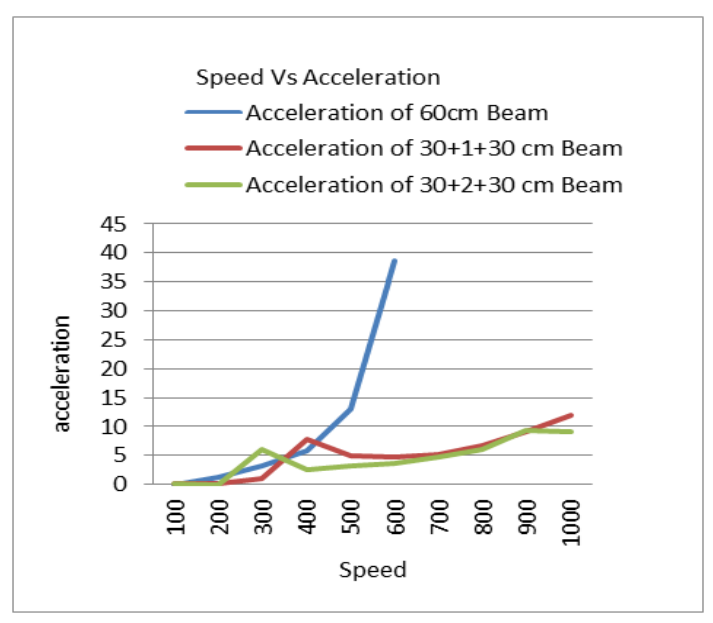

Figure 11. Comparison of Speed Vs Acceleration

The experimental data are segregated on the basis of displacement, velocity and acceleration and graphs are drawn as shown in figs 9-11, between speed Vs displacement, speed Vs velocity and speed Vs acceleration respectively. From the graphs it is clear that fixed wings can be accelerated faster than compliant wings. For the compliant wing the displacement is more than the fixed wing. Interestingly, the displacements and velocity of wings are more at certain speed hinting at proper selection of parameters for the wing could improve performance (speeding capability) and also the effort required to effect deformation can be reduced.

\section{CONCLUSION}

In this paper the suitability of a nonlinear model to study the dynamics of a selectively deformable wing has been investigated. For this purpose a single cantilever beam and a beam with selectively compliance representing the aircraft wings are modeled and studied by subjecting them to sinusoidal excitation. The effect of stiffness on acceleration and displacement capability are studied. It is found that stiffer beams (wings) can be accelerated or decelerated faster and undergo less deformation. It is difficult to accelerate the wing with more compliance. Experiments conducted on (stiff) beams and compliant beams conforms the theoretical findings. Further, this preliminary study demonstrates that the dynamics of deformable wing can be studied using a nonlinear model as both (theoretical and experimental) results show comparable dynamic characteristics. In future, the model will be refined further and investigations will be made to arrive at a suitable selectively deformable wing for the aircrafts.

\section{REFERENCES}

[1] John D. Anderson, Jr, "Aircraft Performance and Design", Mc Graw-Hill International Editions, Aerospace Science/Technology Series 1999.

[2] Gennady Amiryants, Fanil Ishmuratov, Victor Malyutin, Victor Timokhin, "Selectively Deformable Structures For Design Of Adaptive Wing Smart Elements" ICAS2010 27th International Congress Of The Aeronautical Sciences.

[3] John Simpson,Luis Anguita,Bo Nilsson, Vincenzo-Vaccaro, Gregorio kawiecki , "Review Of The European Research Project "Active Aeroelastic Aircraft Structures" (3AS) European Conference For Aerospace Sciences (EUCASS)

[4] V. Brailovski, P. Terriault, T. Georges, D. Coutu, "SMA Actuators for Morphing Wings" 3rd International Symposium on Shape Memory Materials for Smart Systems, Physics Procedia 00 (2010) .

[5] Svetlana Kuzmina, Gennadi Amiryants, Johannes Schweiger, Jonathan Cooper, Michael Amprikidis, Otto Sensberg, "Review And Outlook On Active And Passive Aeroelastic Design Concepts For Future Aircraft" ICAS 2002 CONGRESS pp. $432.1-432.10$.

[6] Gennady Amiryants, "Active Aeroelasticity Concept: Novel View, Methodology And Results" ICAS2008, 26th International Congress Of The Aeronautical Sciences.

[7] B. Nagel, H.P. Monner, E. Breitbach, "Integrated Design Of Smart Composites, Applied To Smart Winglets" ICAS2008 25th International Congress Of The Aeronautical Sciences.

[8] G.A.Amiryants, F.Z. Ishmuratov, S.I. Kuzmina, "Use Of Aeroelasticity; Multidisciplinary Investigations" ICAS2004 24th International Congress Of The Aeronautical Sciences. 
[9] Ohsung Ahn, J.M. Kim, C.H. Lim, "Smart Uav Research Program Status Update : Achievement Of Tilt-Rotor Technology, Development And Vision Ahead" ICAS2010 27th International Congress Of The Aeronautical Sciences.

[10] Christoph K. Maucher, Boris A. Grohmann, Peter Jänker, Andree Altmikus,

[11] Flemming Jensen, Horst Baier, "Actuator Design For The Active Trailing Edge Of A Helicopter Rotor Blade"

[12] Eli Livnes, "Future of Airplane Aeroelasticity" Journal of Aircraft, Vol. 40, No. 6, November-December 2003.

[13] Michele Bonnin, "Harmonic Balance, Melnikov method and Nonlinear Oscillators Under resonant Pertuberation"

[14] 13.Chion-Fong Chung, Chiang-Nan Chang, " Dynamics of Asymmetric Nonlinear vibration Absorber" Journal of Marine Science and Technology, Vol. 1, No.1, pp. 8-19(2003).

[15] 15.S.J. Zhu, Y.F. Zheng, Y.M. Fu, "Analysis of non-linear dynamics of a two-degree-of-freedom vibration system with non-linear damping and non-linear spring", Journal of sound and vibration 271 (2004) 15-24.

[16] Zhu Weiqiu, Wu Qitai, "Jump and bifuction of duffing oscillator under narrow-band excitation" ACTA MECHANICA SINICA, Vol.10, No.1, February 1994, science press, Beijing, china, Allerton Press, INC., New York, U.S.A.

[17] Yebin Wang, Kenji Utsunomiya, Scoot A. Bortoff, "Nonlinear Control Design for a Semi-Active Vibration Reduction System" Proceedings of the 30th Chineese Control Conference, July 22-24, 2011, Yantai, China. 